\title{
14-3-30 induces heat shock protein 70 expression in hepatocellular carcinoma
}

\author{
Chia-Chia Liu ${ }^{1,2+}{ }^{+}$, Yee-Jee Jan ${ }^{3 \dagger}$, Bor-Sheng Ko ${ }^{4 \dagger}$, Yao-Ming Wu ${ }^{5}$, Shu-Man Liang ${ }^{2}$, Shyh-Chang Chen ${ }^{3}$, \\ Yen-Ming Lee ${ }^{6}$, Tzu-An Liu'², Tzu-Ching Chang ${ }^{2,7,8}$, John Wang ${ }^{3}$, Song-Kun Shyue ${ }^{6}$, Li-Ying Sung ${ }^{1 *}$ \\ and Jun-Yang Liou ${ }^{2,9^{*}}$
}

\begin{abstract}
Background: $14-3-3 \sigma$ is implicated in promoting tumor development of various malignancies. However, the clinical relevance of 14-3-30 in hepatocellular carcinoma (HCC) tumor progression and modulation and pathway elucidation remain unclear.

Methods: We investigated 14-3-3 $\sigma$ expression in 109 HCC tissues by immunohistochemistry. Overexpression and knockdown experiments were performed by transfection with cDNA or siRNA. Protein expression and cell migration were determined by Western blot and Boyden chamber assay.

Results: In this study, we found that 14-3-30 is abundantly expressed in HCC tumors. Stable or transient overexpression of 14-3-30 induces the expression of heat shock factor-1a (HSF-1a) and heat shock protein 70 (HSP70) in HCC cells.

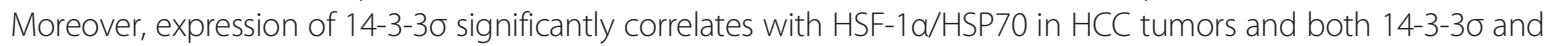
HSP70 overexpression are associated with micro-vascular thrombi in HCC patients, suggesting that 14-3-30/HSP70 expression is potentially involved in cell migration/invasion. Results of an in vitro migration assay indicate that 14-3-30 promotes cell migration and that 14-3-30-induced cell migration is impaired by siRNA knockdown of HSP70. Finally, 14-3-30-induced HSF-1a/HSP70 expression is abolished by the knockdown of $\beta$-catenin or activation of GSK-3 $\beta$.

Conclusions: Our findings indicate that 14-3-30 participates in promoting HCC cell migration and tumor development via $\beta$-catenin/HSF-1 a/HSP70 pathway regulation. Thus, 14-3-30 alone or combined with HSP70 are potential prognostic biomarkers for HCC.
\end{abstract}

Keywords: 14-3-3б, $\beta$-catenin, Hepatocellular carcinoma, HSF-1, HSP70

\section{Background}

The 14-3-3 family of proteins regulates multiple cellular processes with a highly conserved homology among all eukaryotic cells $[1,2]$. The 14-3-3 $\sigma$ isoform (also known as stratifin, SFN) sequesters Cdc2-cyclin B and $\mathrm{Cdc} / \mathrm{Cdk}$ complexes in the cytoplasm, thereby inducing a G2 cell cycle arrest $[3,4]$. Transcriptional expression of $14-3-3 \sigma$ is directly activated by the p53 tumor suppressor protein [5].

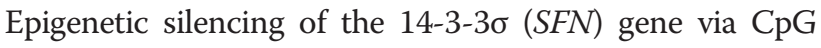
methylation has been reported in various cancer cells, including: breast, lung, liver, gastric cancer, ovarian and

\footnotetext{
*Correspondence: liyingsung@ntu.edu.tw; jliou@nhri.org.tw

${ }^{\dagger}$ Equal contributors

${ }^{1}$ Institute of Biotechnology, National Taiwan University, Taipei 106, Taiwan

${ }^{2}$ Institute of Cellular and System Medicine, National Health Research

Institutes, Zhunan 350, Taiwan

Full list of author information is available at the end of the article
}

prostate cancers [6,7]. However, an increasing number of studies have demonstrated that 14-3-3 $\sigma$ overexpression promotes tumor progression [8-15]. An earlier study has indicated that frequent hypermethylation of $\mathrm{CpG}$ islands and the elimination of 14-3-3 $\sigma$ expression is found in human hepatocellular carcinoma (HCC) [16]. In contrast, increased 14-3-3 $\sigma$ expression was found in a proteomic study conducted to identify HCC associated protein markers [17]. These results, suggesting a "bipolar" role for 14-3-36, may be due to specific tissues, cell types, signaling pathways or may depend on the tumor-associated microenvironment.

Several molecular markers, including heat shock protein 70 (HSP70), glypican 3 (GPC3) and glutamine synthetase (GS) were proposed as diagnostic markers of hepatocellular nodules in cirrhosis and early HCC [18-24]. Among these potential diagnostic factors, HSP70 is also considered as a 
drug target for cancer therapy $[25,26]$. HSP70 is an essential molecular chaperon and is activated in response to stress and cell survival protection. It is tightly controlled by the upstream transcriptional factor heat shock factor-1 (HSF-1). Recent studies have indicated that HSF-1 is a key determinant in cancer progression and increased HSF-1 expression promotes $\mathrm{HCC}$ tumor invasion and metastasis $[27,28]$. These results suggest that HSF-1 and HSP70 are involved in facilitating $\mathrm{HCC}$ tumor development. Although the molecular mechanism of HSF-1's transcriptional regulation is not well elucidated, some evidence indicates that the activation of glycogen synthase kinase$3 \beta$ (GSK-3 3 ) signaling attenuates HSF-1 activity [29-31]. GSK- $3 \beta$ is a serine/threonine protein kinase and a dysregulation in GSK-3 $\beta$ signaling has been suggested to be critical in influencing HCC cell growth [32]. GSK-3 $\beta$ phosphorylates $\beta$-catenin and subsequently facilitates $\beta$-catenin ubiquitination/degradation [33]. Accumulation or mutations of $\beta$-catenin increase cell proliferation and are associated with tumor progression in HCC [34-37].

The aim of the present study is to evaluate the role of 14-3-3 $\sigma$ in HCC and to investigate the potential molecular targets of $14-3-3 \sigma$ in modulating HCC development. Our data indicates that 14-3-3 $\sigma$ expression is elevated in HCC tumors and increased 14-3-3 $\sigma$ expression promotes HCC tumor formation. Moreover, we show for the first time that 14-3-3 $\sigma$ induces HSP70 expression which induces cell migration via a $\beta$-catenin/HSF-1 dependent pathway. Our results reveal that HSP70 is the downstream regulator of 14-3-3 $\sigma$ which modulates HCC development. A combination of 14-3-3 $\sigma$ with HSF-1 and/or HSP70 might therefore be considered as potential prognostic biomarkers for HCC.

\section{Methods}

\section{Clinical specimens}

Tissue samples were obtained from $109 \mathrm{HCC}$ patients who had undergone surgery for tumor resection at Taichung Veterans General Hospital from January 1999 to December 2001. Twenty-nine patients (26.6\%) developed tissue-proven metastases, 3 to 87 months after resecting the primary HCC. Slides from paraffin-embedded surgical specimens, including the metastatic tumors and primary tumors with surrounding non-cancerous liver parenchyma, were subjected to immunohistochemical (IHC) staining. The IHC staining results were compared with pathological features, clinical parameters, including Barcelona-Clinic Liver Cancer (BCLC) staging, and disease outcomes. This study was approved by the Institutional Review Board of Taichung Veterans General Hospital. The policy that no informed consents are required for using these de-linked samples for retrospective analysis was also approved by the Institutional Review Board.

\section{Immunohistochemical analysis}

Procedure of IHC analysis was performed as previously described [38-41]. 14-3-36, HSF-1 and HSP70 expressions in paraffin-embedded tissues were detected by use of primary antibodies against 14-3-3 $\sigma$ (Bethyl Laboratories, Montgomery, TX), HSF-1 and HSP70 (Santa Cruz Biotechnology, Heidelberg, Germany). A negative control was prepared by using the same staining procedure without primary antibodies. The IHC staining intensity was semiquantitatively scored by the Quick-score (Q-score) method based on intensity and heterogeneity, as described previously [38-43]. Briefly, the Q-score of a given tissue sample is the sum of the intensity and heterogeneity scores and ranges from 0 to 7 . A Q-score $\geq 2$ was considered as overexpressed or positive expression and a Q-score $<2$ was considered normal or negative expression. Cases with $<5 \%$ weakly stained specimens were considered as negative expression.

\section{Cell culture and stable cells}

Huh-7 and SK-Hep1 cells were maintained in a humidified incubator with $5 \% \mathrm{CO}_{2}$ at $37^{\circ} \mathrm{C}$ in Dulbecco's modified Eagle's medium (DMEM) (Gibco, Gaithersburg, MD) supplemented with $10 \%$ fetal bovine serum (FBS; Hyclone Thermo Fisher Scientific, Waltham, MA), $100 \mathrm{U} / \mathrm{mL}$ penicillin and $100 \mathrm{U} / \mathrm{mL}$ streptomycin. To establish stable cell lines, $14-3-3 \sigma$ cDNA was amplified by PCR and subcloned into the p3XFlag-CMV vector. Huh-7 cells were transfected with p3XFlag-CMV (control) and 14-3-3 $\sigma$ tagged with Flag

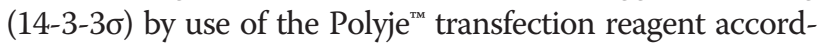
ing to the manufacturer's instructions (SignaGen Laboratories, Rockville, MD). The transfected cells were selected using $500 \mu \mathrm{g} / \mathrm{mL}$ G418 (Biochrom AG, Berlin, Germany) for 4 weeks. Single colonies of control and 14-3-3 $\sigma$ stable clones (at least 4 in each cell line) were maintained in DMEM with $10 \% \mathrm{FBS}$ and $200 \mu \mathrm{g} / \mathrm{mL}$ G418.

\section{Western blot analysis}

Cells were lysed with ice cold RIPA buffer $(0.5 \mathrm{~mol} / \mathrm{L}$ Tris-HCl, pH 7.4, $1.5 \mathrm{~mol} / \mathrm{L} \mathrm{NaCl}, 2.5 \%$ deoxycholic acid, 10\% NP-40, 10 mmol/L EDTA; Millipore, Temecula, CA) containing a protease inhibitor cocktail (Roche, Indianapolis, IN). Cell lysates were centrifuged at $16,100 \mathrm{~g}$ at $4^{\circ} \mathrm{C}$ for 20 minutes. Protein concentrations were determined and $20 \mu \mathrm{g}$ of total proteins were applied to the gradient SDS-PAGE gel and immunoblotted onto PVDF membranes. The membranes were blocked, incubated with primary antibodies against Flag (Sigma-Aldrich, St. Louis, MO), 14-3-3 $\sigma$ (Abcam PLC, Cambridge, UK), HSF-1, $\beta$ catenin (Cell Signaling Technology, Beverly, MA) or HSP70 (Santa Cruz Biotechnology, Heidelberg, Germany), followed by an incubation with a secondary antibody conjugated horseradish-peroxidase in PBST. Protein levels were determined by the use of enhanced chemiluminescence reagents. 


\section{Cell proliferation assay}

Cell proliferation was analyzed using a 3-(4,5-dimethylthiazol-2-yl)-2,5-dipheny ltetrazoliumbromide (MTT) assay as previously reported [38]. Briefly, cells were seeded in 96-well plates at a density of 1500 cells/well for 0, 24, 48 and 72 hours. $20 \mu \mathrm{L}$ of MTT $(5 \mathrm{mg} / \mathrm{ml}$ ) (Sigma, St. Louis, MO) was added to each well and incubated at $37^{\circ} \mathrm{C}$ for 3 hours. Subsequently, the MTT solution was removed, DMSO was added and the absorbance value (OD) of each well was measured at $570 \mathrm{~nm}$ with a reference wavelength of $690 \mathrm{~nm}$.

\section{Quantitative real-time PCR}

Total RNA was extracted by use of the RNAspin Mini Kit (QIAGEN, Alameda, CA) and cDNA was synthesized from 2 to $5 \mu \mathrm{g}$ RNA by use of the random primers and SuperScript $^{\text {ti }}$ III Reverse Transcriptase cDNA Synthesis Kit (Invitrogen $^{\text {twx }}$ Life Technology, Carlsbad, CA). Quantitative real-time PCR using SYBR Green (Kapabiosystem, Woburn, MA) with specific oligonucleotide primers of HSF-1 and HSP0 (Additional file 1: Table S1) were detected by the AB 7900HT system (Applied Biosystems, Carlsbad, CA). Applied Biosystems Relative Quantification Manager Software version 1.2 was used to analyze the relative gene expression in each sample by the comparative cycle threshold $(\mathrm{Ct})$ method. Gene expression was normalized to that of glyceraldehyde-3-phosphate dehydrogenase.

\section{Transfection and siRNA knockdown}

Targeted knockdown of the 14-3-3 $\sigma$ gene expressions with siRNA was purchased from Invitrogen ${ }^{\mathrm{Tw}}$ including scramble siRNA (Cat.No.12935-112). siRNA for targeting HSP70 (sc-29352) and HSF-1 (sc-35611) were purchased from Santa Cruz (Additional file 1: Table S2). Cell transfections with siRNAs were performed using Lipofectamine $^{\mathrm{Tu}}$ RNAiMAX (Invitrogen, Grand Island, NY) and harvested at the indicated time for further analysis.

\section{Migration assay}

The cell migration assay was performed in a Boyden chamber with Bio-coat cell migration chambers (Becton Dickinson, Pont-de-Claix, France) as described previously [38]. Cells were trypsinized, re-suspended with $0.1 \%$ bovine serum albumin (BSA)-DMEM and added to the upper wells $\left(5 \times 10^{4}\right.$ cells for Huh-7 stable cells, $2 \times 10^{4}$ cells for SK-Hep1 cells). The cells then migrated to the bottom wells that contained medium with $100 \mu \mathrm{g} / \mathrm{mL}$ fibronectin (Becton Dickinson, Pont-de-Claix, France), epidermal growth factor $(20 \mathrm{ng} / \mathrm{mL}$ ), and $10 \%$ BSA. The cells remaining on the upper well were removed and the migrating cells in the bottom well were stained and fixed with $0.1 \%$ crystal violet containing 20\% ethanol and 1\% formaldehyde for 20 minutes. Efficiency of cell migration was quantified by counting the total number of migrating cells.

\section{Statistical analysis}

One-way analysis of variance (ANOVA) was used to analyze differences among clinicopathological variables by

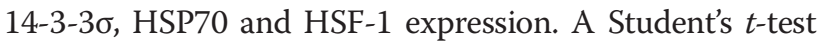
was used to analyze differences between 2 experimental groups. A $P$ value $<0.05$ was considered statistically significant and a $P$ value of between 0.05 and 0.10 was considered marginally significant.

\section{Results}

\section{Increased expression of $14-3-3 \sigma$ in HCC tumors}

To determine the expression of $14-3-3 \sigma$ in HCC, paraffinembedded primary HCC tumors with surrounding noncancerous tissues of 109 patients were examined by immunohistochemical staining. 14-3-3 $\sigma$ was undetected or was stained with the background in non-cancerous cells but had significantly increased expression in 84 of 109 (77.1\%) primary HCC tumors (Figure 1A, right panel and Table 1). We next compared 14-3-3 $\sigma$ expression with the clinicopathological characteristics and found that increased 14-3$3 \sigma$ expression was significantly associated with surgical margin $(P=0.008)$, capsular formation $(P=0.028)$ and micro-vascular thrombi $(P=0.001)$. These results indicate that expression of 14-3-3 $\sigma$ is associated with a more aggressive tumor behavior and a poor prognosis (Table 1).

\section{4-3-3 $\sigma$ upregulates HSF-1 and HSP70 expression in HCC}

To investigate the role of 14-3-3 $\sigma$ on HCC tumor progression, we examined the expression level of 14-3-3 $\sigma$ in HCC cell lines including Huh-7, HepG2, Hep3B, SK-Hep1 and PLC-5. Although 14-3-3 $\sigma$ was detectable in all tested cell lines, the expression of 14-3-3 $\sigma$ in Huh-7 was barely detected but there was strong expression in SK-Hep1, PLC-5 and HepG2 cells (Figure 1B). In addition, we examined 14-3-3 $\sigma$ levels in non-HCC cells, including human umbilical vein endothelial cells (HUVECs) and 293 cells, and found the expression of 14-3-3 $\sigma$ was undetectable in these cells (Additional file 1: Figure S1). We next established a stable HCC cell line with 14-3-3 $\sigma$ overexpression in Huh7 cells. Huh-7 cells were transfected with p3XFlag-CMV


lected with G418 for 4 weeks. Single colonies were picked and expression of 14-3-3 $\sigma$ was confirmed by Western blot analysis of Flag and 14-3-3 $\sigma$ (Additional file 1: Figure S2A and $\mathrm{B}$ ). Clone 2 of 14-3-3 $\sigma$ and clone 1 of the control were used for the following experiments. To examine whether 14-3-3 $\sigma$ regulates HCC growth, the cell proliferation rate was determined by an MTT assay. 14-3-3 $\sigma$ overexpression has no significant effect on cell proliferation in comparison to the control cells (Figure 1C).

To explore the downstream factors of 14-3-3 $\sigma$ which are involved in modulating HCC tumor progression, we performed a gene expression profile analysis of 14-3-3 $\sigma$ overexpresion (Additional file 1: Table S3 and Table S4). 

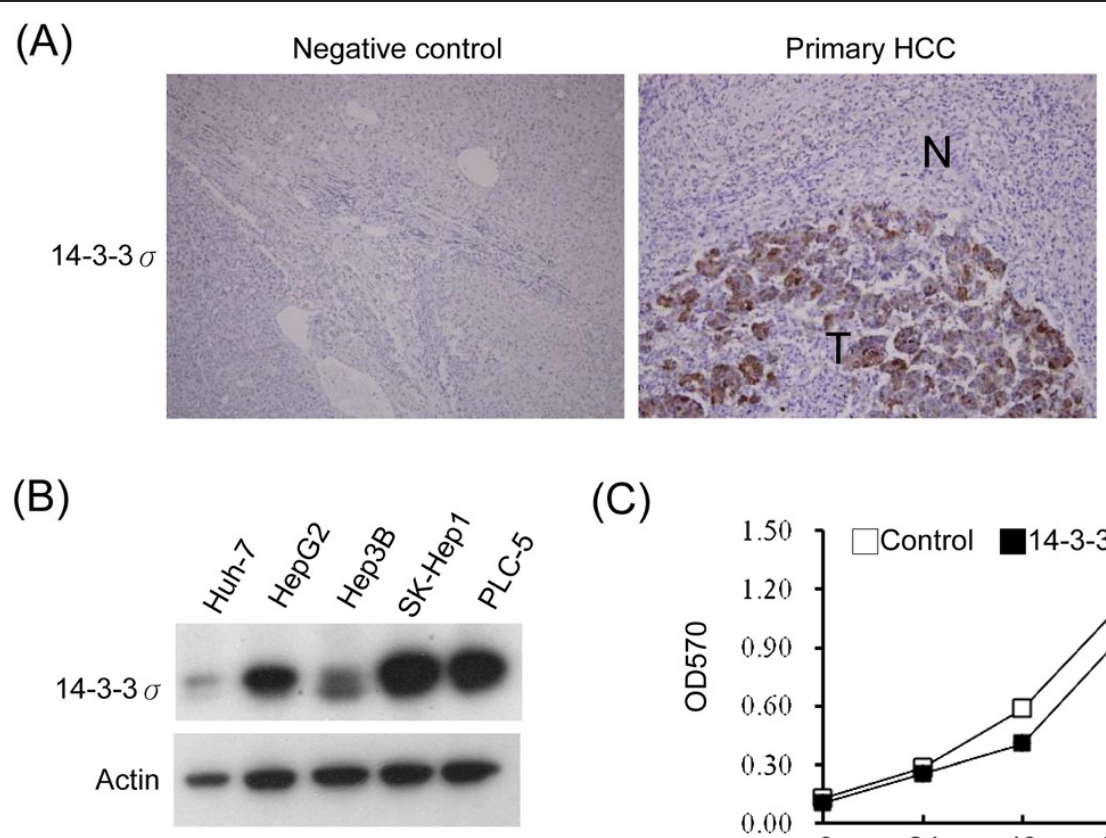

(C)

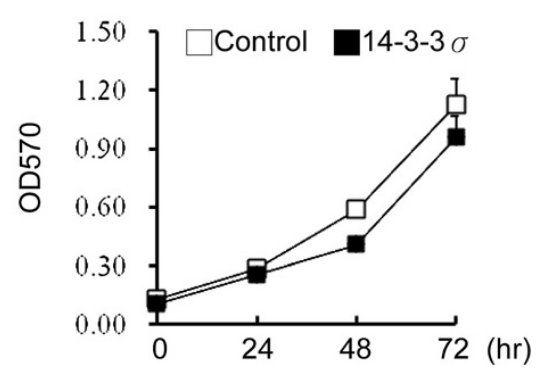

Figure 1 14-3-30 overexpression induces tumor growth. (A) A represtative expression of 14-3-30 in a primary HCC tumor and in a negative control examined by immunohistochemical analysis. T: tumor; N: non-cancerous cells. Original magnification: $\times 200$. (B) 14-3-30 expression levels in HCC cell lines were determined by Western blot analysis. Actin was used as a loading control. (C) The rate of cell proliferation was determined by an MTT assay. Scale bars: mean \pm SD.

Among the genes altered by 14-3-3 $\sigma$ overexpression, we identified HSP70 as one of the potential targets. Earlier studies have suggested that HSP70 serves as a potential biomarker for early detection of HCC [18-23]. To validate whether HSP70 expression is induced by 14-3-30, we determined HSP70 and its transcriptional activator, HSF- $1 \alpha$ levels by Western blot analysis. Stable cells with increased 14-3-3 $\sigma$ expression significantly induced HSF- $1 \alpha$ as well as HSP70 expression levels (Figure 2A). Induction of HSF$1 \alpha /$ HSP70 was further validated on the RNA level by quantitative real-time PCR analysis (Figure $2 \mathrm{~B}$ ). We next performed transient transfection experiments of 14-3-3 $\sigma$ overexpression in HCC cells. Transient overexpression of 14-3-3 $\sigma$ significantly induced HSF- $1 \alpha / \mathrm{HSP} 70$ expression in Huh-7 cells (Figure 2C). Furthermore, 14-3-3б-induced HSF-1 $\alpha$ and HSP70 expressions were attenuated by siRNA knockdown of 14-3-3 $\sigma$ (Figure 2D) and HSF-1 $\alpha$ (Additional file 1: Figure S3). In addition, transfection of $14-3-3 \sigma$ siRNA suppressed HSF-1 $\alpha$ and HSP70 expressions in SK-Hep1 cells (Figure 2E). These results indicate that HSF-1 $\alpha / \mathrm{HSP} 70$ expressions are induced by $14-3-3 \sigma$ in HCC.

\section{Association of 14-3-3 $\sigma$ expression with HSF-1 $a$ and HSP70 in HCC tissues}

To further show that 14-3-3 $\sigma$ induces HSF- $1 \alpha /$ HSP70 in HCC, we examined and compared the expression of HSF$1 \alpha /$ HSP70 with $14-3-3 \sigma$ by immunohistochemical staining in clinical HCC specimens. Both HSF- $1 \alpha$ and HSP70 expression were correlatively increased in HCC tumors (Figure 3A). The expression of HSF- $1 \alpha$ and HSP70 stained positively in 93 of 109 (85.3\%) and 66 of 109 (60.6\%) of primary HCC tumors, respectively. Furthermore, expres-

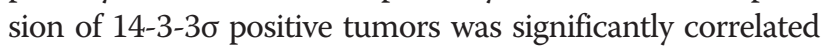
with HSF- $1 \alpha(P<0.001)$ and HSP70 $(P=0.032)$ (Figure 3B). We next analyzed the correlation of HSP70 expression with clinicopathological characteristics and found that positive HSP70 expression was significantly associated with microvascular thrombi $(P=0.019)$ and alpha-fetoprotein levels $(P=0.009)$ (Table 1$)$.

\section{4-3-36/HSP70 enhanced HCC cell migration}

While comparing the expression of $14-3-3 \sigma$ and HSP70 with clinicopathological parameters, the most significant factor is the appearance of micro-vascular thrombi which positivity correlates with both 14-3-3 $\sigma$ and HSP70 (Table 1). Increased micro-vascular thrombi imply enhanced tumor migration/invasion. We therefore wanted to determine whether HSP70 expression influences 14-3-3б-induced cell migration/invasion. We first investigated whether 14-3-3 $\sigma$ overexpression affects cell migration/invasion. $14-3-3 \sigma$ overexpression significantly facilitates cell migration (Figure 4A), although an unexpected effect of suppressing invasion was found (Additional file 1: Figure S4). Moreover, the 14-3-3 $\sigma$ induced migratory ability was significantly abrogated by siRNA knockdown in both of the 14-3-3 $\sigma$ stable cells (Figure 4B) and SK-Hep1 cells 


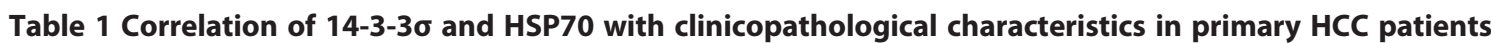

\begin{tabular}{|c|c|c|c|c|}
\hline Parameters & 14-3-3 $\sigma$ expression (Q-score $\geq 2) \%(n)$ & $p$-value & Hsp70 expression (Q-score $\geq 2$ ) \% (n) & $p$-value \\
\hline Overall $(n=109)$ & $77.1 \%(84)$ & & $60.6 \%(66)$ & \\
\hline Age & & $0.080^{\dagger}$ & & NS \\
\hline$<60$ years $(n=56)$ & $83.9 \%(47)$ & & $66.1 \%(37)$ & \\
\hline$\geq 60$ years $(n=53)$ & $69.8 \%(37)$ & & $54.7 \%(29)$ & \\
\hline Gender & & NS & & $0.097^{\dagger}$ \\
\hline Male $(n=82)$ & $79.3 \%(65)$ & & $56.1 \%(46)$ & \\
\hline Female $(n=27)$ & $70.4 \%(19)$ & & $74.1 \%(20)$ & \\
\hline Histology grade & & NS & & $0.060^{\dagger}$ \\
\hline $1(n=7)$ & $71.4 \%(5)$ & & $28.6 \%(2)$ & \\
\hline $2(n=77)$ & $74.0 \%(57)$ & & $58.4 \%(45)$ & \\
\hline $3(n=25)$ & $88.0 \%(22)$ & & $76.0 \%(19)$ & \\
\hline Types of surgery & & NS & & NS \\
\hline Wedge resection $(n=39)$ & $69.2 \%(27)$ & & $56.4 \%(22)$ & \\
\hline Segmentectomy $(n=54)$ & $79.6 \%(43)$ & & $64.8 \%(35)$ & \\
\hline Lobectomy $(n=16)$ & $87.5 \%(14)$ & & $56.3 \%(9)$ & \\
\hline Surgical margin & & $0.008^{*}$ & & NS \\
\hline Free $(n=83)$ & $71.1 \%(59)$ & & $61.4 \%(51)$ & \\
\hline Involved $(n=26)$ & $96.2 \%(25)$ & & $57.7 \%(15)$ & \\
\hline $\mathrm{BCLC}$ staging & & NS & & $0.079^{\dagger}$ \\
\hline \multicolumn{5}{|l|}{ Not available $(n=5)$} \\
\hline Early (stage $A 1$ to A4) $(n=56)$ & $69.6 \%(39)$ & & $51.8 \%(29)$ & \\
\hline Intermediate (stage B) $(n=46)$ & $82.6 \%(38)$ & & $67.4 \%(31)$ & \\
\hline Advanced (stage C) $(n=2)$ & $100.0 \%(2)$ & & $100.0 \%(2)$ & \\
\hline Tumor size & & $0.062^{\dagger}$ & & $0.062^{\dagger}$ \\
\hline$\geq 5.0 \mathrm{~cm}(\mathrm{n}=34)$ & $88.2 \%(30)$ & & $73.5 \%(25)$ & \\
\hline$<5.0 \mathrm{~cm}(\mathrm{n}=75)$ & $72.0 \%(54)$ & & $54.7 \%(41)$ & \\
\hline Tumor multiplicity & & NS & & NS \\
\hline Single $(n=84)$ & $78.6 \%(66)$ & & $63.1 \%(53)$ & \\
\hline Multiple $(n=25)$ & $72.0 \%(18)$ & & $52.0 \%(13)$ & \\
\hline Capsular formation & & $0.028^{*}$ & & NS \\
\hline \multicolumn{5}{|l|}{ Not available $(n=8)$} \\
\hline Yes $(n=59)$ & $69.5 \%(41)$ & & $57.6 \%(34)$ & \\
\hline No $(n=42)$ & $88.1 \%(37)$ & & $66.7 \%(28)$ & \\
\hline Micro-vascular thrombi & & $0.001^{*}$ & & $0.019^{*}$ \\
\hline Yes $(n=48)$ & $91.7 \%(44)$ & & $72.9 \%(35)$ & \\
\hline No $(n=61)$ & $65.6 \%(40)$ & & $50.8 \%(31)$ & \\
\hline Liver cirrhosis & & NS & & NS \\
\hline \multicolumn{5}{|l|}{ Not available $(n=3)$} \\
\hline Yes $(n=55)$ & $76.4 \%(42)$ & & $58.2 \%(32)$ & \\
\hline No $(n=51)$ & $78.4 \%(40)$ & & $64.7 \%(33)$ & \\
\hline Viral hepatitis & & NS & & NS \\
\hline \multicolumn{5}{|l|}{ Not available $(n=7)$} \\
\hline Hepatitis B $(n=54)$ & $79.6 \%(43)$ & & $61.1 \%(33)$ & \\
\hline Hepatitis C $(n=30)$ & $70.0 \%(21)$ & & $56.7 \%(17)$ & \\
\hline
\end{tabular}




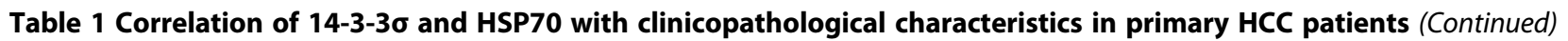

\begin{tabular}{|c|c|c|c|c|}
\hline Both $(n=15)$ & $80.0 \%(12)$ & & $60.0 \%(9)$ & \\
\hline None $(n=3)$ & $66.7 \%(2)$ & & $66.7 \%(2)$ & \\
\hline Alpha-fetoprotein level & & NS & & $0.009^{*}$ \\
\hline \multicolumn{5}{|l|}{ Not available $(n=12)$} \\
\hline$\geqq 80 \mathrm{ng} / \mathrm{ml}(\mathrm{n}=35)$ & $80.0 \%(28)$ & & $77.1 \%(27)$ & \\
\hline$<80 \mathrm{ng} / \mathrm{ml}(\mathrm{n}=62)$ & $74.2 \%(46)$ & & $50.0 \%(31)$ & \\
\hline Subsequent extrahepatic metastasis & & NS & & NS \\
\hline Yes $(n=29)$ & $82.8 \%(24)$ & & $65.5 \%(19)$ & \\
\hline No $(n=80)$ & $75.0 \%(60)$ & & $58.8 \%(47)$ & \\
\hline
\end{tabular}

BCLC, Barcelona-Clinic Liver Cancer; NS, not significant; Q-score, Quick-score. ${ }^{*} p<0.05 ;{ }^{\dagger} 0.05<p<0.10$.

(A)

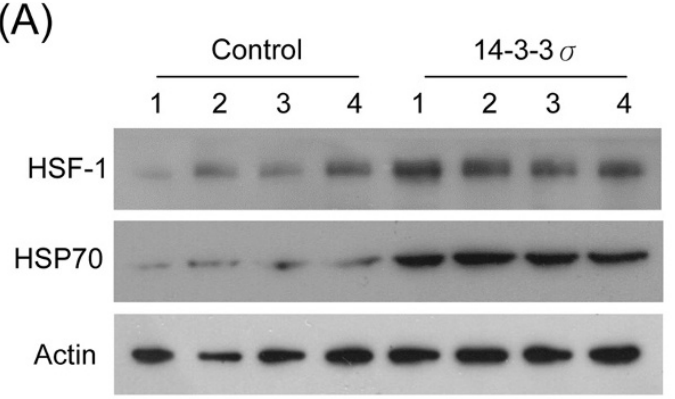

(B)

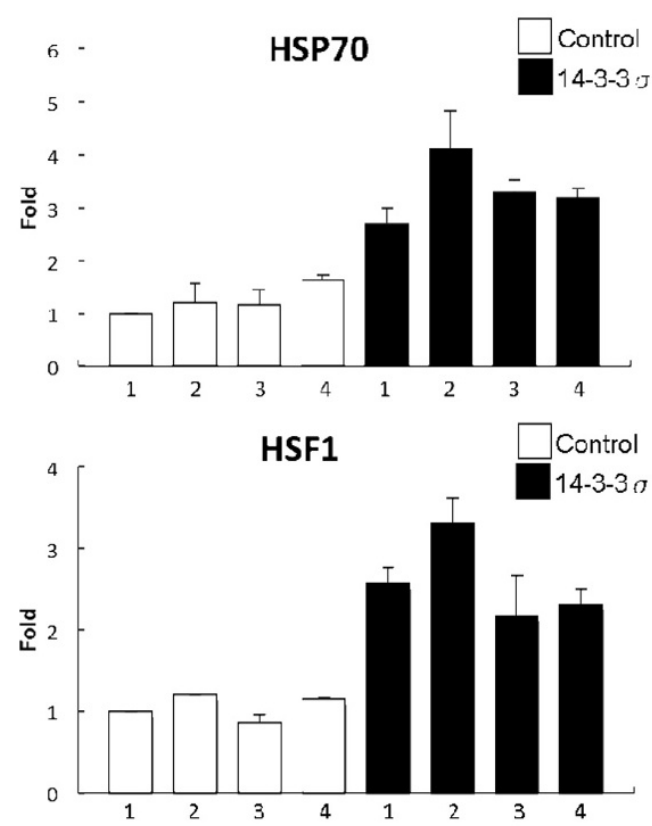

(C)

\section{Control $14-3-3 \sigma$}

HSF-1

HSP70

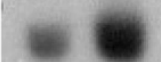

Flag

Actin
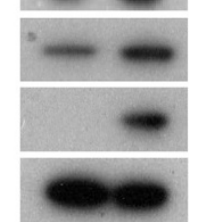

(D)

Control $\sigma$ Control $\sigma$

HSF-1

HSP70

Flag

Actin

Scramble siRNA $++\quad+\quad-$

14-3-3 $\sigma$ SiRNA - -++

(E)

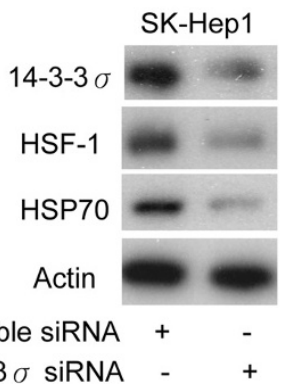

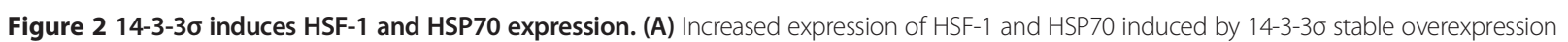
was determined by Western blotting and (B) real-time PCR analysis. Lanes 1-4 indicate as 4 different stable clones selected from the single colonies.

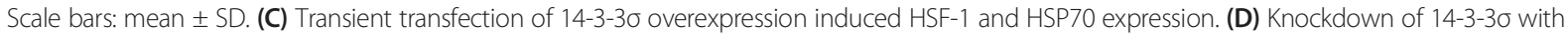

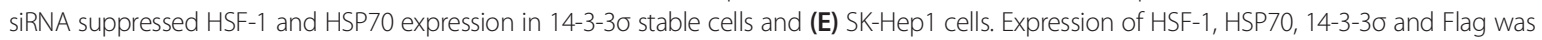
determined by Western blot analysis. Actin was used as a loading control. 


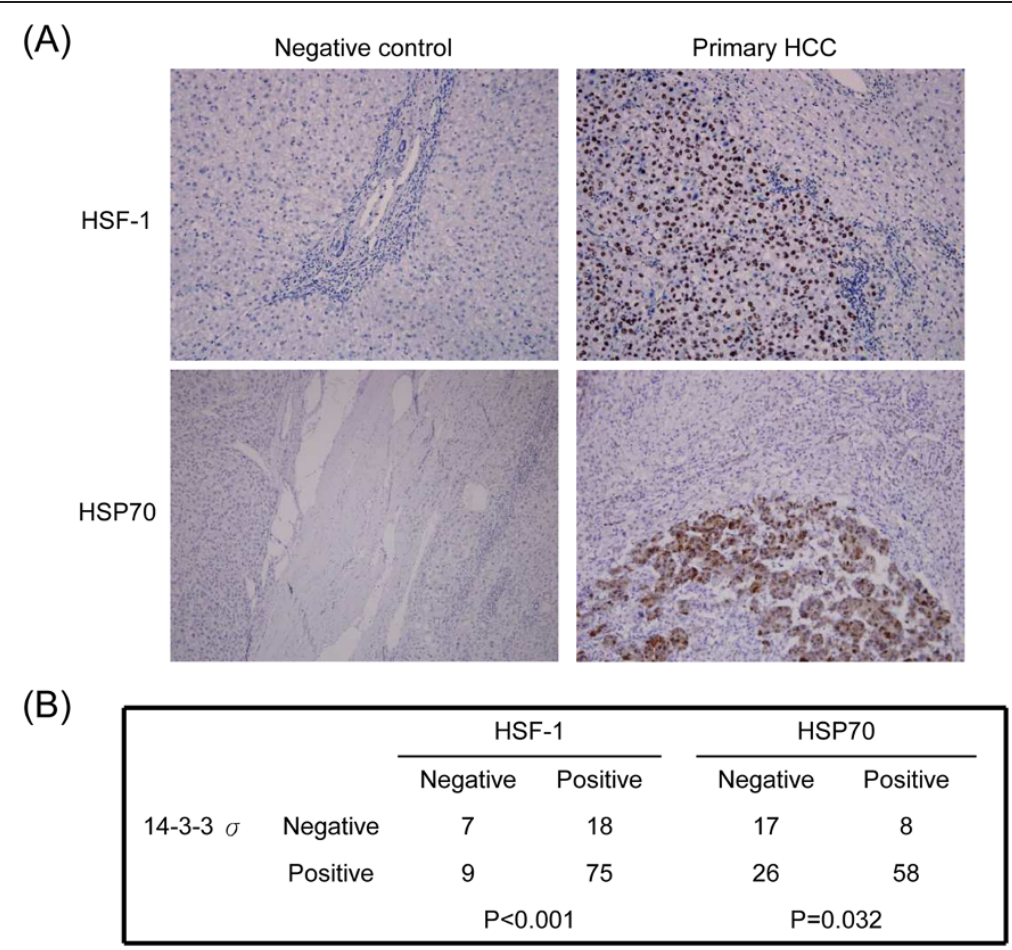

Figure 3 Correlation of 14-3-3 $\sigma$ expression with HSF-1 and HSP70 in HCC tumors. (A) Representative expression of HSF-1 and HSP70 in primary HCC tumors as well as negative control was examined by immunohistochemical analysis. Original magnification, $\times 200$. (B) 14-3-30 significantly correlates with HSF-1 and HSP70 expression in primary HCC tumors as analyzed by the Chi-square test.

(Figure 4C). These results indicate that increased 14-3-30 expression results in promoting HCC cell migration. To

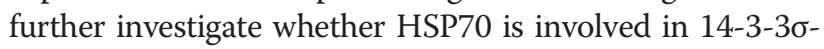
induced cell migration, SK-Hep1 cells overexpressing 143-3 $\sigma$ were transfected with HSP70 siRNAs. Knockdown of HSP70 significantly impaired 14-3-3б-induced cell migration in stable (Figure 4D) and in SK-Hep1 cells (Figure 4E). These results indicate that HSP70 is an important downstream regulator of $14-3-3 \sigma$ which in turn regulates $\mathrm{HCC}$ cell migration and tumor progression.

\section{4-3-3 $\sigma$ induces HSF-1 $\alpha$ expression via a GSK-3 $\beta / \beta$-catenin dependent mechanism}

HSP70 is transcriptionally upregulated by HSF- $1 \alpha$ activation. The molecular pathway controlling HSF-1 $\alpha$ expression has never been well characterized. Earlier studies indicate that GSK-3 $\beta$ modulates HSF-1 $\alpha$ activity [29-31] and the stability of $\beta$-catenin is known to be the major downstream event regulated by GSK-3 $\beta$. We thus postulated that GSK-3 $\beta / \beta$-catenin may be involved in regulating $14-3-3 \sigma$-induced HSF-1 $\alpha /$ HSP70 expression. To prove this hypothesis, $14-3-3 \sigma$ overexpressing and control cells were transfected with $\beta$-catenin or scramble siRNA and the expression of HSF- $1 \alpha$ was determined by Western blot analysis. Knockdown of $\beta$-catenin significantly abrogates 14-3$3 \sigma$-induced HSF- $1 \alpha$ expression (Figure $5 \mathrm{~A}$ ). The effects of HSF- $1 \alpha$ and HSP70 suppressive expressions by $\beta$ - catenin knockdown were also confirmed in SK-Hep1 cells (Figure 5B). In addition, we found that $14-3-3 \sigma$ overexpression increases $\beta$-catenin expression levels (Figure $5 \mathrm{~A}$ and C). Transient activation of GSK-3 $\beta$ by transfection of wild type (GSK-3 $\beta$ WT) or constitutively activated mutant (GSK-3 $\beta$ CA) significantly attenuates $14-3-3 \sigma$-induced $\beta$ catenin and HSF- $1 \alpha$ expression (Figure $5 \mathrm{C}$ ). We next examined whether $\beta$-catenin is involved in regulating cell migration of HCC. The 14-3-3б/control cells and SKHep1 cells were transfected with siRNA of $\beta$-catenin and the migration ability was determined by a trans-well assay. Knockdown of $\beta$-catenin significantly reduced cell migra-

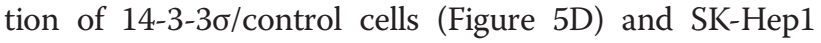
cells (Figure 5E). These results suggest that $14-3-3 \sigma$ induced HSF-1 $\alpha / \mathrm{HSP70}$ expression and cell migration is mediated by the GSK-3 $\beta / \beta$-catenin signaling pathway.

\section{Discussion}

Our results show that $14-3-3 \sigma$ plays major roles in HCC. We initially showed that $14-3-3 \sigma$ is overexpressed in HCC tumors and that HSP70, one of the downstream factors of $14-3-3 \sigma$, is upregulated by $14-3-3 \sigma$ and this action is mediated by the GSK- $3 \beta / \beta$-catenin/HSF- $1 \alpha$ signaling pathway. Additionally, $14-3-3 \sigma$ modulates HSP70 to promote cell migration in HCC. These findings suggest that $14-3-3 \sigma$ together with $\beta$-catenin/HSF- $1 \alpha$ and HSP70 enhance HCC tumor progression. 14-3-3 $\sigma$ was shown to both enhance 


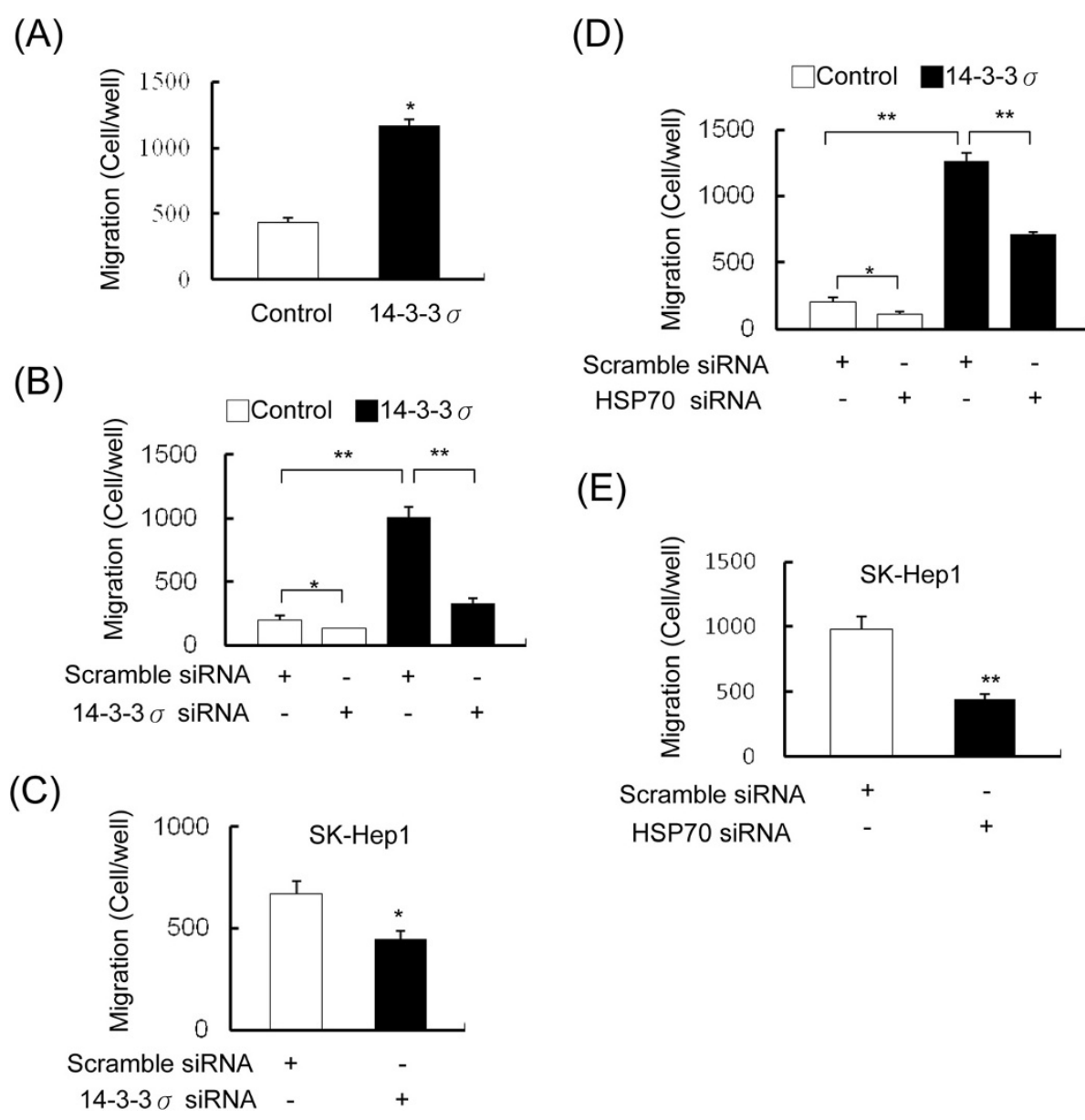

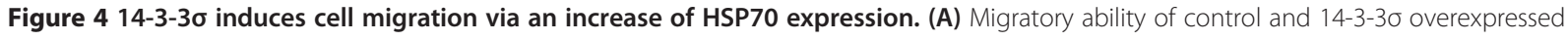

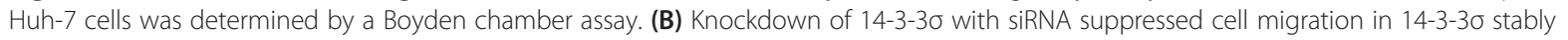
overexpressed Huh-7 cells and (C) SK-Hep1 cells. (D) Knockdown of HSP70 with siRNA attenuated 14-3-3б-induced cell migration in stable cells and (E) SK-Hep1 cells. Scale bars: mean \pm SD. ${ }^{*} P<0.05,{ }^{* *} P<0.01$.

and restrict malignant tumor progression in different tumor types pointing to a cell type specific effect of 14-3$3 \sigma$. For instance, $14-3-3 \sigma$ is frequently DNA hypermethylation and subsequently silenced in lung cancers. However,


erogeneous lung cancers [44]. Recent studies have demonstrated that a highly methylated SFN promoter is found in normal lung tissue and in adenocarcinomas [13], however, $14-3-3 \sigma$ is overexpressed in early invasive adenocarcinoma $[13,15]$. These studies indicate that $14-3-3 \sigma$ expression in tumors is modulated by a complicated regulatory mechanism. In addition, analysis of 14-3-3 $\sigma$ and HSP70 expressions with clinicopathological parameters reveal that both 14-3-3 $\sigma$ and HSP70 are correlated with micro-vascular thrombi in HCC patients. We have shown that 14-3-30 overexpression induces $\mathrm{HCC}$ cell migration (Figure 4A) but unexpectedly reduces cell invasion (Additional file 1: Figure S4). These results reveal that the $14-3-3 \sigma$ promotion of $\mathrm{HCC}$ cell invasion and tumor metastasis are complicated processes and other essential synergistic regulators are probably involved. By simply elevating 14-3-3 $\sigma$ expression without activating other synergistic factors may result in a reciprocal phenomenon. This may also explain the duplicitous role of 14-3-3 $\sigma$ reported in earlier studies $[16,17]$. In addition, since extracellularly secreted $14-3-3 \sigma$ has been shown to affect muscle remodeling in keratinocyte associated fibroblasts [44], we postulate that the surrounding stromal cells associated with tumors play important roles in 14-3-3б-promoting HCC tumor progression. 14-3$3 \sigma$ might synergize with other signals from its microenvironment milieu and tumor-stromal interactions may therefore be critical for tumor progression. Further investigation needs to be done to ascertain if $14-3-3 \sigma$ combines with additional factors and if 14-3-3б's expression in tumor heterogeneity is found in distinct stages of HCC.

We found that either the moderate (clone 1 and 2) or extremely higher (clone 3 and 4) expression of 14-3-36 (Additional file 1: Figure S2B) upregulate the expression of 

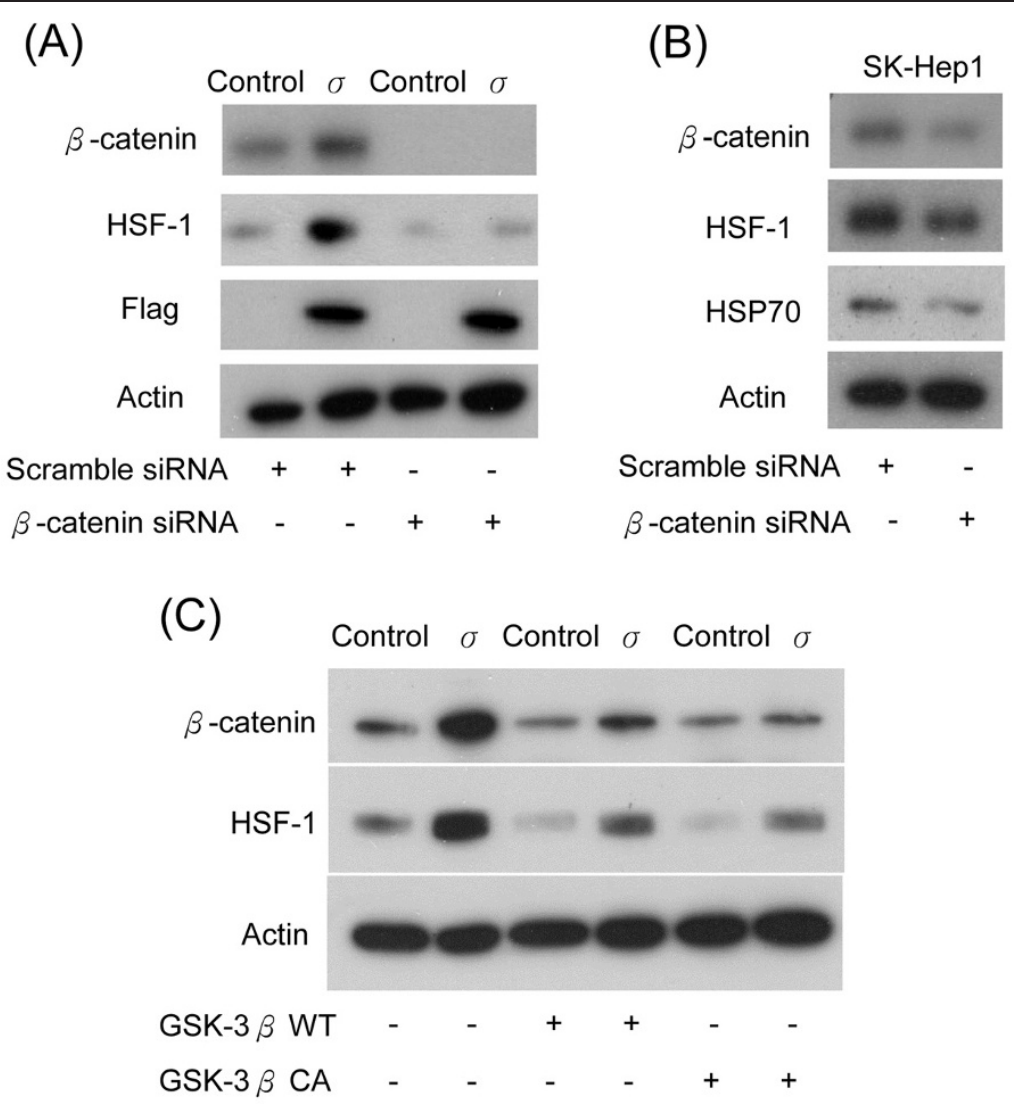

(D)

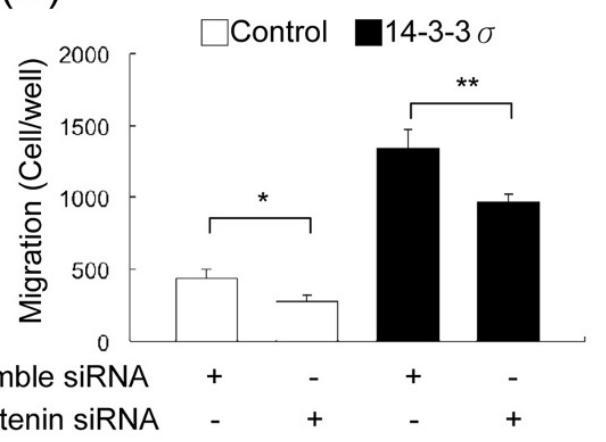

$(\mathrm{E})$

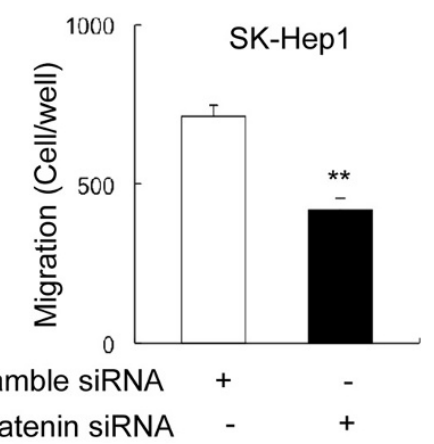


$\beta$-catenin in stable cells and (B) SK-Hep1 cells. (C) 14-3-30-induced HSF-1 expression was attenuated by overexpression with wild type (WT) and constitutively activated (CA) mutant of GSK-3 $\beta$. Expression of $\beta$-catenin, HSF-1, HSP70 and Flag was determined by Western blot analysis. Actin was used as a loading control. (D) Migratory ability was determined by a Boyden chamber assay. Knockdown of $\beta$-catenin with siRNA suppressed cell migration in 14-3-30 stably overexpressed cells and (E) SK-Hep1 cells. Scale bars: mean \pm SD. ${ }^{*} P<0.05,{ }^{* *} P<0.01$.

HSF- $1 \alpha$ and HSP70 (Figure 2A and B). These results suggest that the appropriately increased $14-3-3 \sigma$ expression may be sufficient to regulate $\mathrm{HCC}$ tumor progression and an excess of $14-3-3 \sigma$ have no further effect on HSF- $1 \alpha$ and HSP70 expression (Figure 2A and B).

In this work, we show for the first time that HSF-1 $\alpha$ / HSP70 is regulated by $\beta$-catenin in HCC. $\beta$-catenin is an important transcriptional regulator in promoting cell proliferation. Our recently published data indicates that 14-3-
$3 \sigma$ promotes mouse embryonic stem cell proliferation via enhancing $\beta$-catenin stability [45], suggesting that $14-3-3 \sigma$ may modulate the $\beta$-catenin signal pathway to promote cell proliferation. In addition, earlier studies have indicated that $\beta$-catenin signaling regulates GS expression and is involved in glutamine metabolism [46,47]. Since $\beta$-catenin is known to be a pivotal factor in promoting HCC development [34-37], both HSF- $1 \alpha / \mathrm{HSP} 70$ and GS are potential downstream targets of $\beta$-catenin. Whether the potential 
TCF/LEF binding motifs found on the promoters of HSF-1 and GS are regulated by $\beta$-catenin needs further investigation.

\section{Conclusion}

Our results link 14-3-3 $\sigma$ with $\beta$-catenin/HSF- $1 \alpha / \mathrm{HSP} 70$ and these regulators work as a network in promoting HCC development. We also provide evidence at the cellular and clinical tissue levels to suggest that $14-3-3 \sigma$ is the upstream modulator of $\beta$-catenin and HSF- $1 \alpha / \mathrm{HSP70}$ in HCC. 14-3-3 $\sigma$ combined with other potential markers including HSP70 might be used as potential prognostic biomarkers for HCC.

\section{Additional file}

Additional file 1 Table S1. Oligonucleotide sequences for Q-PCR. Table S2. Oligonucleotide sequences of small interfering RNAs. Table S3. Gene expression ( $>4$ fold) induced by 14-3-30 overexpression in Huh-7 stable cells was analyzed by microarray analysis. The total RNA samples were extracted from control and 14-3-30 overexpressed cells using Qiagen RNeasy Mini Kit (Qiagen, Valencia, CA) and the microarray analysis was processed according to the manufacturers' instructions of Affymetrix Inc. (Santa Clara, CA). Table S4. Gene expression ( $<4$ fold) suppressed by 14-3-30 overexpression was analyzed by microarray analysis. Figure $\mathbf{S 1}$. Expression of 14-3-30 in non-HCC (HUVECS and 293) and HCC (Huh-7, HepG2 and SK-Hep1) cells was determined by Western blotting analysis. Actin was used as loading control. Figure S2. Establishment of 14-3-30 stable cell lines. Huh-7 cells were transfected with p3XFlag-CMV (control) and Flag-tagged 14-3-30 overexpression vectors, followed by selection with G418 for 4 Weeks. Expression of 14-3-30 in stable cells was confirmed by Western blot analysis of (A) Flag and (B) 14-3-30 (4 clones for each of control and 14-3-30). Actin was used as loading control. Figure S3. 14-3-30-induced HSP70 expression was attenuated by knockdown of HSF-1 with siRNA. Control and 14-3-30 stable cells were transfected with scramble or HSF-1 siRNA. Expression of HSF-1 and HSP70 was determined by Western blotting analysis. Actin was used as loading control. Figure S4. 14-3-30 reduces cell invasion. Efficacy of cell invasion was examined by two-chamber analysis.

\section{Competing interests}

The authors declare that they have no competing interests.

\section{Authors' contributions}

CCL, YJJ, BSK, SML, SCC, YML, TAL, TCC conducted experiments; JYL, YJJ, BSK, $C C L, L Y S$ participated in the design of this experiments; JYL, YJJ, BSK, YMW, JW, SKS, LYS analyzed the data; JYL wrote the manuscript; All authors read and approved the final manuscript.

\section{Acknowledgement}

We thank the Comprehensive Cancer Center of Taichung Veterans General Hospital for providing information concerning the outcomes of patients. We also thank the core laboratory of National Health Research Institutes for the helpful assistance. This work was supported by the National Health Research Institutes (01A1-CSPP07-014) and the National Science Council (101-2321-B-400-011, 98-2320-B-400-008-MY3) to JYL; the Taichung Veterans General Hospital (TCVGH-1025801B) to YJj; and the Department of Health (DOH-100-TD-C-111-001) to BSK of Taiwan.

\section{Author details}

IInstitute of Biotechnology, National Taiwan University, Taipei 106, Taiwan ${ }^{2}$ Institute of Cellular and System Medicine, National Health Research Institutes, Zhunan 350, Taiwan. ${ }^{3}$ Department of Pathology and Laboratory Medicine, Taichung Veterans General Hospital, Taichung 407, Taiwan. ${ }^{4}$ Department of Internal Medicine, National Taiwan University Hospital, Taipei 100, Taiwan. ${ }^{5}$ Department of Surgery, National Taiwan University Hospital,
Taipei 100, Taiwan. ${ }^{6}$ Institute of Biomedical Sciences, Academia Sinica, Taipei 115, Taiwan. ${ }^{7}$ Graduate Institute of Clinical Medical Science, China Medical University, Taichung 404, Taiwan. ${ }^{8}$ Metabolomic Medicine Research Center, China Medical University, Taichung 404, Taiwan. ${ }^{9}$ Graduate Institute of Basic Medical Science, China Medical University, Taichung 404, Taiwan.

Received: 21 June 2013 Accepted: 6 June 2014

Published: 12 June 2014

\section{References}

1. Aitken A: Post-translational modification of 14-3-3 isoforms and regulation of cellular function. Semin Cell Dev Biol 2011, 22(7):673-680.

2. Yang X, Lee WH, Sobott F, Papagrigoriou E, Robinson CV, Grossmann JG, Sundstrom M, Doyle DA, Elkins JM: Structural basis for protein-protein interactions in the 14-3-3 protein family. Proc Natl Acad Sci U S A 2006 103(46):17237-17242.

3. Chan TA, Hermeking H, Lengauer C, Kinzler KW, Vogelstein B: 14-3-3Sigma is required to prevent mitotic catastrophe after DNA damage. Nature 1999, 401:616-620.

4. Laronga C, Yang HY, Neal C, Lee MH: Association of the cyclin-dependent kinases and 14-3-3 sigma negatively regulates cell cycle progression. J Biol Chem 2000, 275(30):23106-23112.

5. Li Z, Liu JY, Zhang JT: 14-3-3sigma, the double-edged sword of human cancers. Am J Transl Res 2009, 1(4):326-340.

6. Lodygin D, Hermeking HL: Epigenetic silencing of 14-3-3sigma in cancer. Semin Cancer Biol 2006, 16(3):214-224.

7. Hermeking H: The 14-3-3 cancer connection. Nat Rev Cancer 2003, 3(12):931-943.

8. Neupane D, Korc M: 14-3-3sigma modulates pancreatic cancer cell survival and invasiveness. Clin Cancer Res 2008, 14(23):7614-7623.

9. Guweidhi A, Kleeff J, Giese N, El Fitori J, Ketterer K, Giese T, Büchler MW, Korc M, Friess H: Enhanced expression of 14-3-3sigma in pancreatic cancer and its role in cell cycle regulation and apoptosis. Carcinogenesis 2004, 25(9):575-1585. 1.

10. Perathoner A, Pirkebner D, Brandacher G, Spizzo G, Stadlmann S, Obrist P, Margreiter $R$, Amberger A: 14-3-3sigma expression is an independent prognostic parameter for poor survival in colorectal carcinoma patients. Clin Cancer Res 2005, 11(9):3274-3279.

11. Ide M, Saito K, Tsutsumi S, Tsuboi K, Yamaguchi S, Asao T, Kuwano H, Nakajima T: Over-expression of 14-3-3sigma in budding colorectal cancer cells modulates cell migration in the presence of tenascin-C. Oncol Rep 2007, 18(6):1451-1456.

12. Zhou WH, Tang F, XU J, Wu X, Feng ZY, Li HG, Lin DJ, Shao CK, Liu Q: Aberrant upregulation of 14-3-3o expression serves as an inferior prognostic biomarker for gastric cancer. BMC Cancer 2011, 11:397.

13. Shiba-Ishii A, Noguchi M: Aberrant stratifin overexpression is regulated by tumor-associated $\mathrm{CpG}$ demethylation in lung adenocarcinoma. Am J Pathol 2012, 180(4):1653-1662.

14. Radhakrishnan VM, Jensen TJ, Cui H, Futscher BW, Martinez JD: Hypomethylation of the 14-3-3sigma promoter leads to increased expression in non-small cell lung cancer. Genes Chromosomes Cancer 2011, 50(10):830-836.

15. Shiba-Ishii A, Kano J, Morishita Y, Sato Y, Minami Y, Noguchi M: High expression of stratifin is a universal abnormality during the course of malignant progression of early-stage lung adenocarcinoma. Int I Cancer 2011, 129(10):2445-2453.

16. Iwata N, Yamamoto H, Sasaki S, Itoh F, Suzuki H, Kikuchi T, Kaneto H, Iku S, Ozeki I, Karino Y, Satoh T, Toyota J, Satoh M, Endo T, Imai K: Frequent hypermethylation of $\mathrm{CpG}$ islands and loss of expression of the 14-3-3 sigma gene in human hepatocellular carcinoma. Oncogene 2000, 19(46):5298-5302.

17. Chen XL, Zhou L, Yang J, Shen FK, Zhao SP, Wang YL: Hepatocellular carcinoma-associated protein markers investigated by MALDI-TOF MS. Mol Med Report 2010, 3(4):589-596.

18. Chuma M, Sakamoto M, Yamazaki K, Ohta T, Ohki M, Asaka M, Hirohashi S Expression profiling in multistage hepatocarcinogenesis: identification of HSP70 as a molecular marker of early hepatocellular carcinoma. Hepatology 2003, 37(1):198-207.

19. Di Tommaso L, Destro A, Seok JY, Balladore E, Terracciano L, Sangiovanni A, lavarone M, Colombo M, Jang JJ, Yu E, Jin SY, Morenghi E, Park YN, Roncalli M: The application of markers (HSP70 GPC3 and GS) in liver biopsies is useful for detection of hepatocellular carcinoma. J Hepatol 2009, 50(4):746-754. 
20. Shin E, Ryu HS, Kim SH, Jung H, Jang JJ, Lee K: The clinicopathological significance of heat shock protein 70 and glutamine synthetase expression in hepatocellular carcinoma. J Hepatobiliary Pancreat Sci 2011, 18:544-550.

21. Di Tommaso L, Franchi G, Park YN, Fiamengo B, Destro A, Morenghi E, Montorsi M, Torzilli G, Tommasini M, Terracciano L, Tornillo L, Vecchione R, Roncalli M: Diagnostic value of HSP70, glypican 3, and glutamine synthetase in hepatocellular nodules in cirrhosis. Hepatology 2007, 45(3):725-734.

22. Tremosini S, Forner A, Boix L, Vilana R, Bianchi L, Reig M, Rimola J, Rodríguez-Lope C, Ayuso C, Solé M, Bruix J: Prospective validation of an immunohistochemical panel (glypican 3, heat shock protein 70 and glutamine synthetase) in liver biopsies for diagnosis of very early hepatocellular carcinoma. Gut 2012, 61(10):1481-1487.

23. Sakamoto M: Early HCC: diagnosis and molecular markers. J Gastroentero 2009, 44(Suppl 19):108-111.

24. Li L, Jin R, Zhang X, LV F, Liu L, Liu D, Liu K, Li N, Chen D: Oncogenic activation of glypican-3 by c-Myc in human hepatocellular carcinoma. Hepatology 2012, 56(4):1380-1390.

25. Wang RE: Targeting heat shock proteins $70 / 90$ and proteasome for cancer therapy. Curr Med Chem 2011, 18(27):4250-4264.

26. Evans CG, Chang L, Gestwicki JE: Heat shock protein 70 (hsp70) as an emerging drug target. J Med Chem 2010, 53(12):4585-4602.

27. Jin X, Moskophidis D, Mivechi NF: Heat shock transcription factor 1 is a key determinant of HCC development by regulating hepatic steatosis and metabolic syndrome. Cell Metab 2011, 14(1):91-103.

28. Fang F, Chang R, Yang L: Heat shock factor 1 promotes invasion and metastasis of hepatocellular carcinoma in vitro and in vivo. Cancer 2012, 118(7):1782-1794.

29. He B, Meng YH, Mivechi NF: Glycogen synthase kinase 3beta and extracellular signal-regulated kinase inactivate heat shock transcription factor 1 by facilitating the disappearance of transcriptionally active granules after heat shock. Mol Cell Biol 1998, 18(1):6624-6633.

30. Bijur GN, Jope RS: Opposing actions of phosphatidylinositol 3-kinase and glycogen synthase kinase-3beta in the regulation of HSF-1 activity. J Neurochem 2000, 75(6):2401-2408.

31. Carmichael J, Sugars KL, Bao YP, Rubinsztein DC: Glycogen synthase kinase3beta inhibitors prevent cellular polyglutamine toxicity caused by the Huntington's disease mutation. J Biol Chem 2002, 277(37):33791-33798.

32. Desbois-Mouthon C, Blivet-Van Eggelpoel MJ, Beurel E, Boissan M, Delelo R, Cadoret A, Capeau J: Dysregulation of glycogen synthase kinase-3beta signaling in hepatocellular carcinoma cells. Hepatology 2002, 36(6):1528-1536.

33. Welsh Gl, Wilson C, Proud CG: GSK3: a SHAGGY frog story. Trends Cell Biol 1996, 6(7):274-279

34. Prange W, Breuhahn K, Fischer F, Zilkens C, Pietsch T, Eilers R, Dienes HP, Schirmacher P: Beta-catenin accumulation in the progression of human hepatocarcinogenesis correlates with loss of E-cadherin and accumulation of p53, but not with expression of conventional WNT-1 target genes. J Pathol 2003, 201(2):250-259.

35. Inagawa S, Itabashi M, Adachi S, Kawamoto T, Hori M, Shimazaki J, Yoshimi F, Fukao K: Expression and prognostic roles of beta-catenin in hepatocellular carcinoma: correlation with tumor progression and postoperative survival. Clin Cancer Res 2002, 8(2):450-456.

36. Nhieu JT, Renard CA, Wei Y, Cherqui D, Zafrani ES, Buendia MA: Nuclear accumulation of mutated beta-catenin in hepatocellular carcinoma is associated with increased cell proliferation. Am J Pathol 1999, 155(3):703-710.

37. Wong CM, Fan ST, Ng IO: Beta-catenin mutation and overexpression in hepatocellular carcinoma: clinicopathologic and prognostic significance. Cancer 2001, 92(1):136-145.

38. Liu TA, Jan YJ, Ko BS, Chen SC, Liang SM, Hung YL, Hsu C, Shen TL, Lee YM, Chem PF, Wang J, Shyue SK, Liou J: Increased expression of 14-3-3beta promotes tumor progression and predicts extrahepatic metastasis and worse survival in hepatocellular carcinoma. Am J Pathol 2011, 179 (6):2698-2708

39. Ko BS, Chang TC, Hsu C, Chen YC, Shen TL, Chen SC, Wang J, Wu KK, Jan YJ, Liou Y: Overexpression of 14-3-3epsilon predicts tumour metastasis and poor survival in hepatocellular carcinoma. Histopathology 2011, 58(5):705-711.

40. Ko BS, Lai IR, Chang TC, Liu TA, Chen SC, Wang J, Jan JY, Liou JY: Involvement of 14-3-3gamma overexpression in extrahepatic metastasis of hepatocellular carcinoma. Hum Pathol 2011, 42(1):129-135.
41. Jan YJ, Ko BS, Hsu C, Chang TC, Chen SC, Chen SC, Wang J, Liou JY: Overexpressed focal adhesion kinase predicts a higher incidence of extrahepatic metastasis and worse survival in hepatocellular carcinoma. Hum Pathol 2009, 40(10):1384-1390.

42. Barnes DM, Harris WH, Smith P, Millis RR, Rubens RD: Immunohistochemical determination of oestrogen receptor: comparison of different methods of assessment of staining and correlation with clinical outcome of breast cancer patients. Br J Cancer 1996, 74(9):1445-1451.

43. Chang GC, Liu KJ, Hsieh CL, Hu TS, Charoenfuprasert S, Liu HK, Luch KT, Hsu LH, Wu CW, Ting CC, Chen CY, Chen KC, Yang TY, Chou TY, Wang WH, Whang-Png J, Shih NY: Identification of alpha-enolase as an autoantigen in lung cancer: its overexpression is associated with clinical outcomes. Clin Cancer Res 2006, 12(19):5746-5754.

44. Yatabe Y, Osada H, Tatematsu Y, Mitsudomi T, Takahashi T: Decreased expression of 14-3-3sigma in neuroendocrine tumors is independent of origin and malignant potential. Oncogene 2002, 21(54):8310-8319.

45. Chang TC, Liu CC, Hsing EW, Liang SM, Chi YH, Sung LY, Lin SP, Shen TL, Ko BS, Yen BL, Yet SF, Wu KK, Liou JY: 14-3-3sigma regulates beta-catenin-mediated mouse embryonic stem cell proliferation by sequestering GSK-3beta. PLoS One 2012, 7(6):e40193.

46. Zucman-Rossi J, Benhamouche S, Godard C, Boyault S, Grimber G, Balabaud C, Cunha AS, Bioulac-Sage P, Perret C: Differential effects of inactivated Axin1 and activated beta-catenin mutations in human hepatocellular carcinomas. Oncogene 2007, 26(5):774-780.

47. Cadoret A, Ovejero C, Terris B, Souil E, Levy L, Lamers WH, Kitajewski J, Kahn A, Perret C: New targets of beta-catenin signaling in the liver are involved in the glutamine metabolism. Oncogene 2002, 21(54):8293-8301.

doi:10.1186/1471-2407-14-425

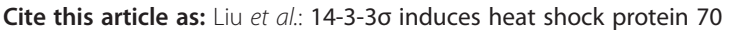
expression in hepatocellular carcinoma. BMC Cancer 2014 14:425.

\section{Submit your next manuscript to BioMed Central and take full advantage of:}

- Convenient online submission

- Thorough peer review

- No space constraints or color figure charges

- Immediate publication on acceptance

- Inclusion in PubMed, CAS, Scopus and Google Scholar

- Research which is freely available for redistribution

Submit your manuscript at www.biomedcentral.com/submit
C) BioMed Central 